\title{
Late results of percutaneous retrograde femoral arterial catheterization in children
}

\author{
R. E. Hawker ${ }^{1}$, Judy Palmer, R. G. Bury, J. D. Bowdler, and J. M. Celermajer \\ From The Adolph Basser Institute of Cardiology, Royal Alexandra Hospital for Children, \\ Sydney, Australia
}

Sixty-six patients under the age of 12 years who had undergone percutaneous retrograde femoral artery catheterization were examined for evidence of sequelae of the procedure. Forty-two patients were considered to be suitable for study for evidence of impairment of circulation and limb growth. Three patients had mild symptoms and no patients had evidence of tissue loss. The detailed results are presented. It is planned to follow this group of 42 patients to later life.

Significant abnormalities of arterial pulses after retrograde arterial catheterization occur in $I$ to 2 per cent of adults (Ross, 1968; Moore et al., 1970; Beckman and Dooley, 1970) and in 2 to 33 per cent of children (Vlad, Hohn, and Lambert, 1964; Desilets, Ruttenberg, and Hoffman, 1966; Simovitch et al., 1970). Though serious morbidity is infrequent (Cahill et al., 1967; Mansfield, Gazzaniga, and Litwin, 1970; Rudolph, 1968), the possibility of impaired limb growth and claudication in later life has been raised (White, Talbert, and Haller, 1968; Rudolph, 1968).

The purpose of this study was to examine, for evidence of impaired arterial supply to the leg, a group of children who had had percutaneous retrograde femoral artery catheterization. It is planned to follow this group to later life.

\section{Subjects and methods}

Patients who had undergone retrograde femoral artery catheterization in the Cardiac Department of the Royal Alexandra Hospital for Children between 1962 and 1968 were recalled for examination. Those unable to attend for geographic or other reasons were examined by their family physicians. All the catheterizations had been performed by the percutaneous Seldinger technique (Seldinger, 1953) using a No. 5 or 6 Gensini catheter. ${ }^{2}$ Information was sought about symptoms such as paraesthesia, pain, colour, limp and coolness, and signs such

Received Is September 1972.

1 Present address: The Johns Hopkins Hospital, Baltimore, U.S.A.

2 U.S.C.I. as temperature, colour texture, hair growth, and lesions of the skin, the presence or absence of various lower limb pulses, and evidence of alterations in lower limb growth.

Data from 66 patients were analysed: 24 patients were then excluded from the study for the following reasons. (a) 17 had subsequent iliac artery cannulation for cardiopulmonary bypass; (b) 5 had pre-existing differences in the two legs, which made relevant comparisons impossible; (c) one had required thromboembolectomy I6 hours after catheterization; and (d) one had coarctation of the aorta and blood pressure could not be recorded in either leg.

The age of the children ranged from 2 to 1 I years. They were examined 3 to 60 months after catheterization.

The study did not examine in detail the duration of the arterial catheterization.

\section{Results}

There was no mortality, no tissue loss, and only the one patient mentioned above required thromboembolectomy for compromised circulation to the leg.

\section{Symptoms}

Symptoms occurred in 2 out of 42 cases. In I of the 2 patients, coolness, pallor, and paraesthesiae persisted for two months before resolving. Examination revealed normal femoral, but decreased popliteal pulses, with the popliteal blood pressure being unrecordable, suggesting obstruction at the adductor hiatus. In the other patient claudication on moderate exertion persisted for several months. 
Palpable reduction in the ipsilateral femoral pulse and a systolic pressure $50 \mathrm{mmHg}$ lower than in the other leg were recorded. In the 24 excluded cases, only one patient had symptoms.

TABLE Systolic pressure difference between catheterized and noncatheterized leg in 42 patients

\begin{tabular}{lr}
\hline $\begin{array}{l}\text { Systolic blood pressure } \\
\text { differential (mmHg) }\end{array}$ & No. \\
\hline $0-10$ & 30 \\
I I-30 & 6 \\
$3 \mathrm{I}-50$ & 0 \\
$5 \mathrm{I}-70$ & 1 \\
$>5 \mathrm{I}$ & 3 \\
Not recorded & 2 \\
\hline \multicolumn{2}{c}{} \\
\end{tabular}

\section{Skin}

No change in skin temperature by palpation, colour, or texture of hair growth was detected in any patient.

\section{Pulses}

In only 3 of 42 patients were palpably decreased femoral pulses noted. In 2 of these the blood pressure in the leg could not be recorded. By contrast, 6 patients in whom the femoral pulses were thought to be normal by palpation, had a pressure differential greater than $10 \mathrm{mmHg}$, though one patient mentioned above probably had obstruction below the femoral triangle.

\section{Blood pressure}

A systolic blood pressure more than $10 \mathrm{mmHg}$ below that in the noncatheterized limb (Toole and Tulloch, 1966; Jeresaty and Liss, 1968) was found in Io of our 42 patients (Table); however, blood pressure was not obtained in 2 who were uncooperative patients.

The number of patients was too small to detect any significant association between reduction in blood pressure in the catheterized leg and either the age of the patient or the underlying condition. However, it is noted that 2 of 3 patients with supravalvar aortic stenosis, a disease known to be associated with widespread narrowing of arteries, had reduced pressure.

\section{Limb size}

Measurements of length and mid-calf diameter from each leg agreed to within \pm 5 per cent in all patients.
The thigh diameter was reduced in only one patient. This child had decreased femoral pulse and unrecordable blood pressure in the leg.

\section{Discussion}

This series is small because in the period considered, retrograde left heart catheterization was not part of routine study but was only performed if some clinical indication existed. The left heart chambers can frequently be entered via a patent foramen ovale and the aorta can be catheterized from the left ventricle by special techniques (Celermajer, Venables, and Bowdler, 1970).

There was no instance of tissue loss, and symptoms were mild and only present in 3 patients. The published material on tissue loss due to postcatheterization arterial thrombosis in children comprises mostly single instances (Cahill et al., 1967; Rudolph, I968; Mansfield et al., 1970). There was no acute tissue loss reported in the large series of Takahashi et al. (1970) and Simovitch et al. (1970) though surgical exploration was performed in Io patients in the latter series, and as with our one case, gangrene might have thus been avoided.

Impaired growth of a limb occurred in 2 of Takahashi et al.'s (1970) patients and in one of White et al. (1968). Disabling claudication occurred in 2 cases reported by Mansfield et al. (1970) and claudication relieved by resection of coarctation of the aorta was reported by Rudolph (1968). Claudication was not described in the series of Takahashi et al. (1970) and Simovitch et al. (1970).

The 7 per cent incidence of palpably reduced pulses in this series compares with the 6 per cent reported by Simovitch et al. (1970) and 3 per cent reported by Kirkpatrick et al. (1970). Favourable results with the percutaneous technique have also been reported by Desilets et al. (1966) and Boijsen and Lundström (1968) though actual numbers were not given. By comparison, absence of distal pulses after brachial arteriotomy occurred in one-third of patients in the series reported by Voci and Hamer (1960) and Vlad et al. (1964). Yet again, these results are at variance with those of Vengsarkar and Swan (1962) and Aguilar, Kaulbach, and Hugenholtz (I966) who felt that return of peripheral pulses occurred within three months of study.

Early return of initially absent pulses may be due to relaxation of arterial spasm (Fogarty and Krippaehne, I965; Aguilar et al., 1966) or to break up and peripheral migration of thrombus (Formanek, Frech, and Amplatz, 1970). Delayed return of pulses can be due to the development of collateral vessels or possibly to recanalization of thrombus (Cahill et al., 1967). 
The number in this series was too small to detect any significant causes predisposing to thrombosis. Reduced pulses occurred most frequently in the younger, small patients in the series of Simovitch et al. (1970). Kirkpatrick et al. (1970) found a statistically significant correlation between low patient weight and the presence of thrombi in the catheter on removal, but no correlation with haemoglobin concentration, arterial spasm, multiple needle punctures, or duration of procedure. However, Formanek et al. (1970) found a relation between thrombus formation and duration of catheterization in their detailed study of thrombus formation.

Reduction in pulses to palpation appeared an insensitive means of detecting impaired circulation. Jeresaty and Liss (1968) using auscultatory blood pressure recordings and Hohn and Craenen (1969) using oscillometry also found palpation a less sensitive method.

From the results of our study and from review of the published material the following is concluded.

a) Return of pulses absent at the conclusion of the arterial catheterization can be anticipated within 8 hours.

b) Absence of distal pulses persisting 8 to 16 hours after arterial catheterization, or inadequate skin circulation, pain, and impaired motor or sensory function are indications for surgical intervention.

c) Persisting absence or reduction of femoral pulses in children can sometimes be associated with claudication which may resolve spontaneously.

d) Persisting absence of reduction in femoral pulses is only rarely associated with impaired limb growth. e) The ultimate outcome of these iatrogenic injuries is as yet unknown.

\section{References}

Aguilar, S., Kaulbach, M. G., and Hugenholtz, P. G. (1966) Retrograde arterial catheterization of the left ventricle in 388 patients. With special reference to aortic-valve disease and coarctation of the aorta. New England fournal of Medicine, 274, 312.

Beckman, C. H., and Dooley, B. (1970). Complications of left heart angiography. A study of 1,000 consecutive cases. Circulation, 41, 825.

Boijsen, E., and Lundström, N.-R. (I968). Percutaneous cardiac catheterization and angiocardiography in infants and children. American fournal of Cardiology, 22, 572.

Cahill, J. L., Talbert, J. L., Ottesen, O. E., Rowe, R. D., and Haller, J. A., Jr. (1967). Arterial complications following cardiac catheterization in infants and children. Fournal of Pediatric Surgery, 2, 134.

Celermajer, J. M., Venables, A. W., and Bowdler, J. D. (1970). Catheterization of the pulmonary artery in transposition of the great arteries. Circulation, 41, ro53.
Desilets, D. T., Ruttenberg, H. D., and Hoffman, R. B. (1966). Percutaneous catheterization in children. Radiology, 87, II9.

Fogarty, T. J., and Krippaehne, W. W. (1965). Vascular occlusion following arterial catheterization. Surgery, Gynecology, and Obstetrics, 121, 1295.

Formanek, G., Frech, R. S., and Amplatz, K. (1970). Arterial thrombus formation during clinical percutaneous catheterization. Circulation, 41, 833.

Hohn, A. R., and Craenen, J. (1969). Arterial pulses following percutaneous catheterization in children. Pediatrics, 43, 617.

Jeresaty, R. M., and Liss, J. P. (1968). Effects of brachial artery catheterization on arterial pulse and blood pressure in 203 patients. American Heart fournal, 76, 48I.

Kirkpatrick, S. E., Takahashi, M., Petry, E. L., Stanton, R. E., and Lurie, P. R. (1970). Percutaneous heart catheterization in infants and children. II. Prospective study of results and complications in 127 consecutive cases. Circulation, 42, 1049.

Mansfield, P. B., Gazzaniga, A. B., and Litwin, S. B. (1970). Management of arterial injuries related to cardiac catheterization in children and young adults. Circulation, 42, 50I.

Moore, C. H., Wolma, F. J., Brown, R. W., and Derrick, J. R. (1970). Complications of cardiovascular radiology. A review of 1,204 cases. American fournal of Surgery, 120, 591.

Ross, R. S. (1968). Arterial complications. Circulation, 37, Suppl. III, 39.

Rudolph, A. M. (1968). Complications occurring in infants and children. Circulation, 37, Suppl. III, 59.

Seldinger, S. I. (1953). Catheter replacement of the needle in percutaneous arteriography. A new technique. Acta Radiologica, 39, 368.

Simovitch, H., Hohn, A. R., Wagner, H. R., Vlad, P., Subramanian, S., and Lambert, E. C. (1970). Percutaneous right and left heart catheterization in children. Experience with I, 000 patients. Circulation, 41, 513.

Takahashi, M., Petry, E. L., Lurie, P. R., Kirkpatrick, S. E., and Stanton, R. E. (1970). Percutaneous heart catheterization in infants and children. I. Catheter placement and manipulation with guide wires. Circulation, 42, 1037.

Toole, J. F., and Tulloch, E. F. (1966). Bilateral simultaneous sphygmomanometry. A new diagnostic test for subclavian steal syndrome. Circulation, 33, 952.

Vengsarkar, A. S., and Swan, H. J. C. (1962). Arteriotomy for cardiac catheterization and angiocardiography in infants and children. Proceedings of the Staff Meetings of the Mayo Clinic, 37, 6r9.

Vlad, P., Hohn, A., and Lambert, E. C. (1964). Retrograde arterial catheterization of the left heart. Circulation, 29, 787.

Voci, G., and Hamer, N. A. J. (1960). Retrograde arterial catheterization of the left ventricle. American fournal of Cardiology, 5, 493.

White, J. J., Talbert, J. L., and Haller, A. J., Jr. (1968). Peripheral arterial injuries in infants and children. Annals of Surgery, 167, 757.

Requests for reprints to Dr. John M. Celermajer, Adolph Basser Institute of Cardiology, Royal Alexandra Hospital for Children, Pyrmont Bridge Road, Camperdown 2050, New South Wales, Australia. 